\begin{tabular}{c} 
International Journal of Engineering \& Technology, $7(4.5)(2018) 213-216$ \\
International Journal of Engineering \& Technology \\
SPC \\
Website: www.sciencepubco.com/index.php/IJET \\
Research paper \\
\hline
\end{tabular}

\title{
Large Format Ceramic Panels Versus Recycled Aluminum Casting Panels: Improvement of the Thermal Behavior of the Museum of Fine Arts of Castellón
}

\author{
Víctor Echarri Iribarren" ${ }^{1}$ Ginés Gómez Castelló, Carlos Rizo Maestre ${ }^{3 *}$ \\ ${ }^{1}$ University of Alicante \\ ${ }^{2}$ University of Alicante \\ ${ }^{3}$ University of Alicante \\ *Corresponding author E-mail: carlosrm@ua.es
}

\begin{abstract}
There is a growing awareness towards the use in architecture of construction materials produced in the area in which the buildings are to be implemented. The reduction of environmental impacts derived from the lower consumption of energy in transportation is significant. In addition, the materials used in the façades have special relevance in the value of the annual energy demand. This fact becomes more important in the case of emblematic buildings with social media impact, both for the quality of their design and for the functional contributions they can make. Sometimes, even for purely aesthetic reasons, the paradox of opting for constructive solutions with worse performance, worse aging, a higher cost of maintenance operations or a higher value of annual energy demand is established. In this research the Museum of Fine Arts of Castellón is analyzed, made with cast aluminum recycled panels as a finishing material on the façade. A comparison is made with the alternative scenario, ventilated ceramic façade, of having used large format ceramic panels, produced in the region, where the ceramic sector is a very important cluster. The reduction of the value of the annual energy demand by $12 \%$ is evaluated by the improvements established in the ventilated ceramic façade.
\end{abstract}

Keywords: large format ceramic, annual energy demand, recycled aluminum, energy efficiency, ventilated façade

\section{Introduction}

The envelopes of the buildings are determinant in their annual demand, in their useful life, durability, thermal and acoustic performance, etc. It is no less important that the aesthetic value or corporate identity that buildings bring to the urban environment or companies, intangible values that are sometimes decisive in decision-making by promoters or designers. Environmental respect is increasingly important, in which buildings are a critical factor in the construction phase, as in the following phases of exploitation or use, rehabilitation or demolition. The analysis of the complete life-cycle assessment (LCA) of the buildings must be carefully drawn and adapted to the social, cultural and economic conditions of each territory.

Numerous investigations have addressed the importance of building envelopes in energy consumption and environmental comfort conditions [1]-[6]. Some of them have shown very interesting results on the performance of ventilated façades, finished in various materials, such as stone, aluminum, bakelized wood [7] or porcelain stoneware [8]. In climates such as the Mediterranean coast, these systems are in summer much of the solar gain due to the heating of the soil layer thanks to the upward convection currents of the ventilated chamber. In winter, part of the solar gain, but with beneficial effects for the drying of moisture from rain and interstitial condensation. The application of a layer of continuous insulation on the outside of the enclosure at the height of the enclosures of a greater internal thermal capacity, controlling and storing the internal thermal loads, while avoiding thermal bridges.
Within this framework, this research is framed, under the hypothesis of an alternative scenario to the constructive solution adopted at the Museum of Fine Arts of Castellón. The project includes in the upper part of its exterior surface an envelope composed of a lining of natural wood, a reinforced concrete wall, and a cast aluminum recycled panel, as it is included in some publications [9], and it has been possible verify in situ. As an alternative to this façade, a large-format ceramic piece is proposed, with particular dimensional characteristics, and its application in the façade by anchoring the substructure of aluminum profiles, generating a ventilated façade with a continuous insulation layer. The thermal behavior of the both envelopes is evaluated in a comparative way, the reduction of the annual energy demand entailed by the proposed solution, as well as the reduction of environmental impacts and $\mathrm{CO} 2$ emissions.

\section{The Museum of Fine Arts of Castellón (MUBAC)}

It is a 7,066 $\mathrm{m} 2$ building on the ground floor, located in the expansion of the Spanish city of Castellón, surrounded by buildings on the ground floor plus seven heights of residential use. It is a complex building, whose main volume resembles a prism with five skylights running from the east façade to the west, with U-glass panels facing north (Fig. 1). It contains five floors of exhibitions, one of them under ground, that communicate through stepped gaps in each floor, so that one could have a diagonal visual of the whole, with the consequent difficulties to endow the building as a 
whole. adequate hygrothermal conditioning, especially for the works of art exhibited there (Fig. 2).

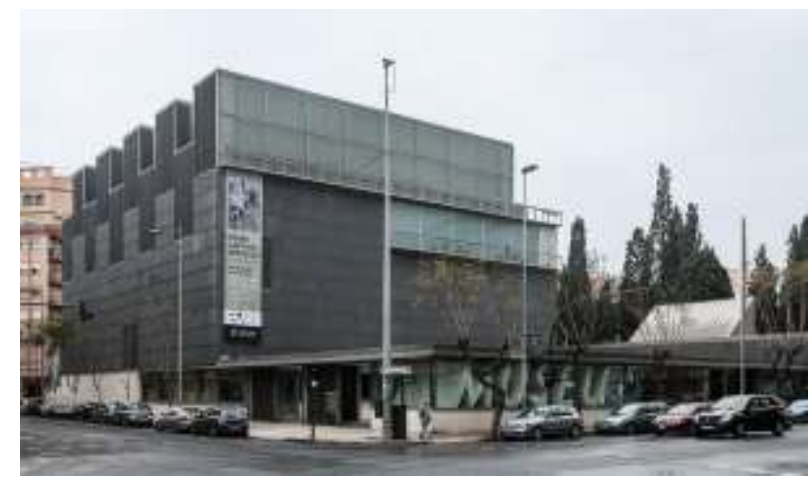

Fig. 1: View of the main volume of the building taken from the northeast.

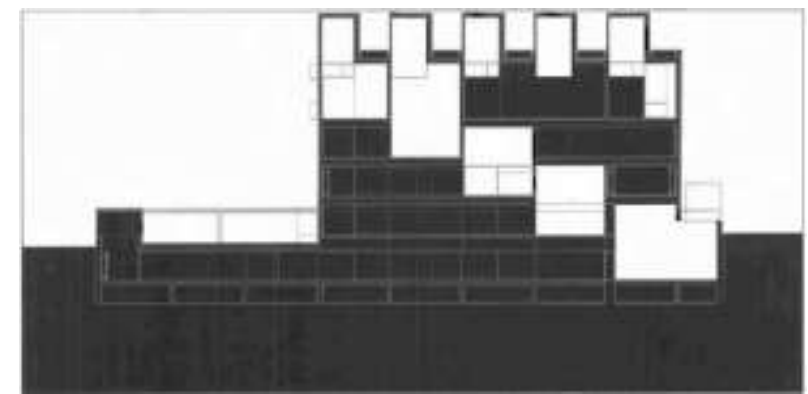

Fig. 2: Longitudinal section with the staging of open exhibition spaces.

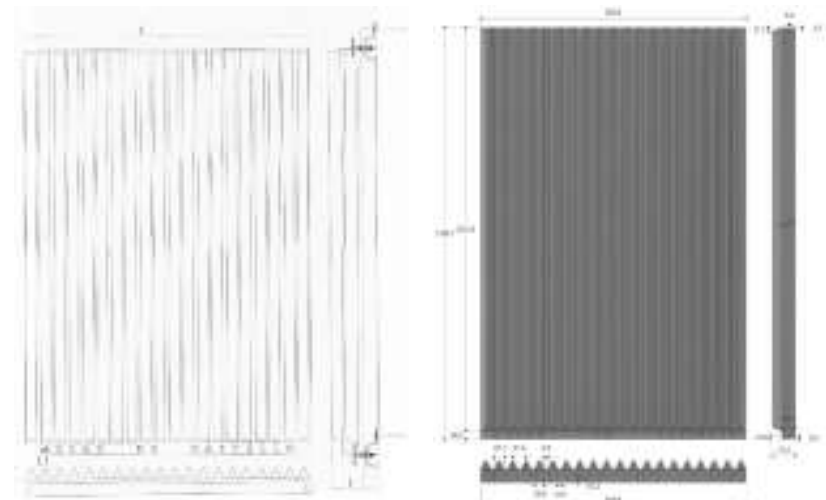

Fig. 3: (a) Recycled aluminum casting panel. (b) Similar piece of largescale porcelain stoneware.

The façade enclosure consists of an internal lining of natural wood on aluminum profiles, reinforced concrete wall of $25 \mathrm{~cm}$. thick, 3 $\mathrm{cm}$ polyurethane insulation layer. of thickness, air chamber and ventilated façade based on cast aluminum recycled panels (Fig. $3 a)$. The value of thermal transmittance $U$ is high $-0.647 \mathrm{~W} /$ $\mathrm{m} 2 \mathrm{~K}$ - having a thermal insulation of only $3 \mathrm{~cm}$. The outer surface of glass is very limited, with a double glazing with a $12 \mathrm{~mm}$. chamber. and Stadip of $6+6$ on both sheets. The roof is inverted flat, with the same finish in cast aluminum recycled, and five skylights run from east to west façade. The northern panel of the skylights, facing north, has been made with U-glass and interior protection of curtains that limit solar gains by radiation.

\section{Methodology}

\subsection{Design of a ceramic piece for the ventilated façade}

The ceramic sector in the Castellón area has been developing advanced technologies in ventilated façade solutions. The pieces or sheets of large-scale porcelain stoneware currently reach a maximum size of $320 \times 160 \mathrm{~cm}$, with a thickness of $9 \mathrm{~mm}$. The weight per square meter is $19 \mathrm{~kg}$., Being a very light material, very resistant and with a water absorption less than $0.5 \%$. These are manufactured by pressing with a roller press, being a complex and delicate technology that requires very purified protocols both in the phase of atomization, wetting and pressing, dehumidification and cooking. The processes of enameling are currently carried out with an inkjet system [10], that is, by means of a printer that applies enamels capable of reproducing in the oven the original colors of any image, photograph or imitation of other materials. These pieces are machined for later anchoring to the substructure arranged in the façade to generate the ventilated façade solution. In addition to the pressing systems, which are the most common, pieces of porcelain stoneware are produced, with absorption of less than $0.5 \%$, by extrusion [11] and molding. In this research, a piece of porcelain stoneware with water absorption of less than $0.5 \%$ is designed, manufactured by means of a molding process as an alternative piece to the existing ones in the MUBAC of recycled aluminum foundry (Fig. 3b). The dimensional and aesthetic characteristics of the finish will be similar to the existing ones, since the enameling processes that are applied allow to copy any chromatic range, texture or property of reflection of the light.

You could get very light pieces of $3.5 \mathrm{~mm}$. of thickness, and a weight per square meter of $10.5 \mathrm{~kg}$ (Fig. 4). Given that the color to follow will be dark gray, due to the similarity with the appearance of recycled aluminum, and that this will present a high absorption of solar radiation, with the consequent heating of the pieces, another innovation is introduced. Reflective enamels similar to those developed by the Keraben group, based on black and brown inorganic pigments, will be used in the infrared range near 700-2500 $\mathrm{nm}$. [12]. The glazed pieces will be baked at $1,180{ }^{\circ} \mathrm{C}$, with the consequent increase in solar reflectance and enamel emissivity. By modifying the composition and microstructure of the glaze, it was possible to increase the reflectance from a value of 0.12 of the conventional piece to a value of 0.31 , for a cold black. Once the enamel has been applied, the water absorption of the piece is reduced to $0.01 \%$, practically non-existent.

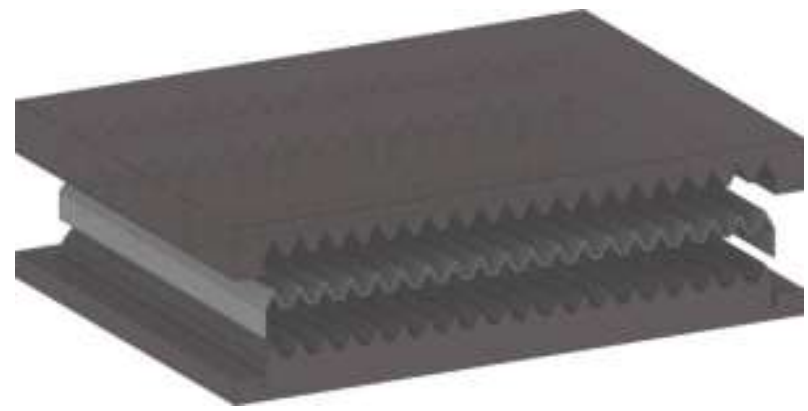

Fig. 4: Pressing the large-format ceramic piece and $3.5 \mathrm{~mm}$ thick.

\subsection{A new façade solution with greater energy efficiency}

The ceramic piece generated has many advantages. It is lighter, and requires a lighter and cheaper anchoring substructure. The increase in reflectance prevents a greater thermal transmission in summer towards the interior layers of the enclosure, reducing the internal thermal admittance Y11 by $35 \%$ [13]. The oscillation of the interior air temperature will therefore be lower in summer. To this must be added the significant reduction in the energy incorporated in the material, the drastic reduction in energy due to transport when manufactured in the Castellón area, and the reduction in annual energy demand. All these factors would produce a significant reduction of environmental impacts in the construction phase and $\mathrm{CO} 2$ emissions.

The most decisive factor is the overall solution of the new façade envelope, in which $9 \mathrm{~cm}$ are incorporated. of mineral wool insulation agglomerated with resins, incombustible, of thermal conductivity $\lambda 0.035 \mathrm{~W} / \mathrm{mk}$, which in addition to avoiding thermal bridges, would allow compliance with the current regulatory requirements, nonexistent at the time of construction of the building [14], [15], both in terms of thermal transmittance $U$ and in the energy rating of the building. The $\mathrm{U}$ value for the proposed façade solution is $0.307 \mathrm{~W} / \mathrm{m} 2 \mathrm{k}$. Fig. 5 shows the two construction sections that are compared in this investigation. Fig. 6 shows the horizontal section of the proposed ceramic piece. 


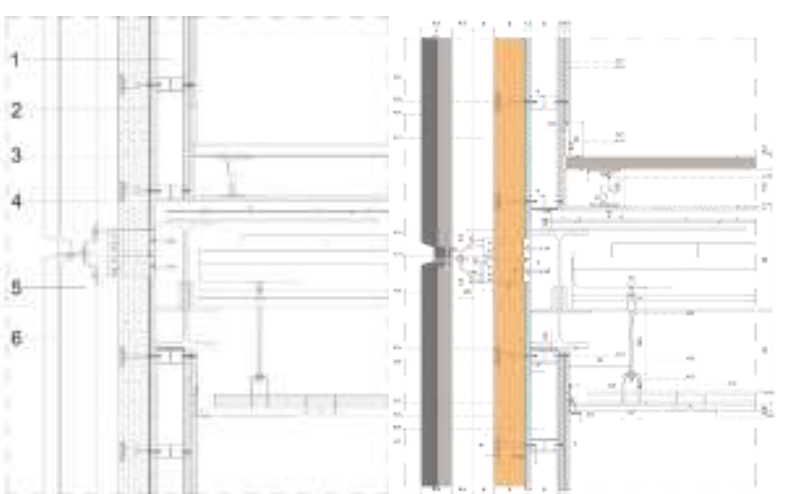

Fig. 5: Typical construction detail of the façade. (a) Current solution. (b) Solution proposed with ceramic pieces.

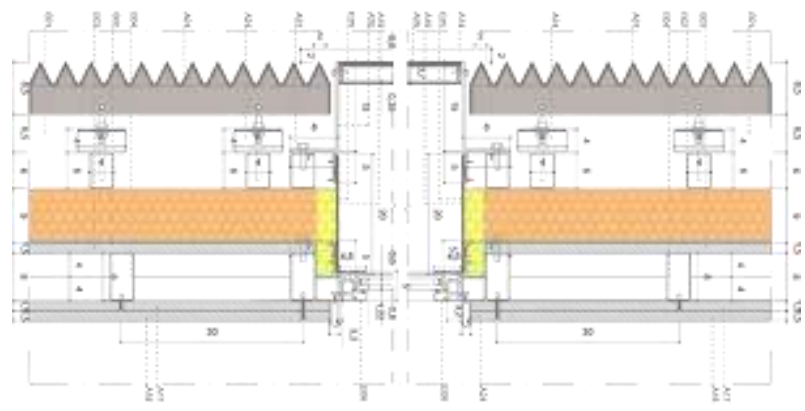

Fig. 6: Detail of the horizontal section of the façade. (a) Current solution. (b) Solution proposed with ceramic pieces.

\section{Results and discussion}

\subsection{Simulation of annual energy demand in the two sce- narios}

The alternative construction solution "MUBAC 2" presents, as we have seen, a significant reduction in the thermal transmittance $U$ of the façade envelope by incorporating a $9 \mathrm{~cm}$. layer. of mineral wool insulation. These benefits of the constructive solution in summer mean a reduction in annual energy demand. For its quantification in the MUBAC 1 and MUBAC 2 scenarios, the Design Builder tool was used (Fig. 7). The winter period covers from December 1 to April 30, and the summer period from May 1 to November 30. It is the protocol established by the MUBAC managers, adjusted to the usual weather conditions in Castellón. The operating hours are 8:00 h. at 7:30 p.m. The internal air setpoint temperatures are $22^{\circ} \mathrm{C}$ in winter and $24^{\circ} \mathrm{C}$ in summer, as indicated by the RITE (CTE) [16]. The occupation, for the normative calculation of air renewal, according to the CTE, is 2,886 people, 0.5 persons per $\mathrm{m} 2$. They must renew 12.5 liters per second and person, which equals 5.62 ren / h. It is obvious that said rate of renewal air is extraordinarily demanding, and that it would entail an excessive energy consumption. The air conditioning project was calculated with the premise of $1 \mathrm{ren} / \mathrm{h}$ of renewal air, value adjusted to the needs of indoor air quality [17]. A global air infiltration rate through the envelope of $0.7 \mathrm{ren} / \mathrm{h}$ has been considered. The reduction in energy demand due to thermal bridges, which was $2.7 \%$, was quantified through the AnTherm tool. The lighting has a power of $5.82 \mathrm{~kW}$. U-glass skylights oriented to the north, of large dimensions, have been considered with curtain protections based on continuous vertical ropes, in their usual state.

The climatic data of the IDAE [18] of dry bulb temperature TS of $4.4{ }^{\circ} \mathrm{C}$ for the design of the heating system, and $31.4{ }^{\circ} \mathrm{C}$ for the design of the refrigeration installation were introduced into the model. For this, a TH bulb temperature of $23.5^{\circ} \mathrm{C}$ was adopted, an average daily oscillation (OMD) of $11.4^{\circ} \mathrm{C}$, an average external air speed of $2.84 \mathrm{~m} / \mathrm{s}$, and a dominant direction of WNW-NW $\left(315^{\circ}\right)$. The minimum temperature for the design of the refrigeration installation -difference between TS and OMD- was therefore $20^{\circ} \mathrm{C}$. The HVAC system, incorporated in the Desgin Builder tool, is made up of air conditioners and fan-coils with four tubes distributed by zones, with cold and hot water circuits of simultaneous power supply, produced in 6 air-water heat pumps of 100,000 fr / $\mathrm{h}$ each of power.

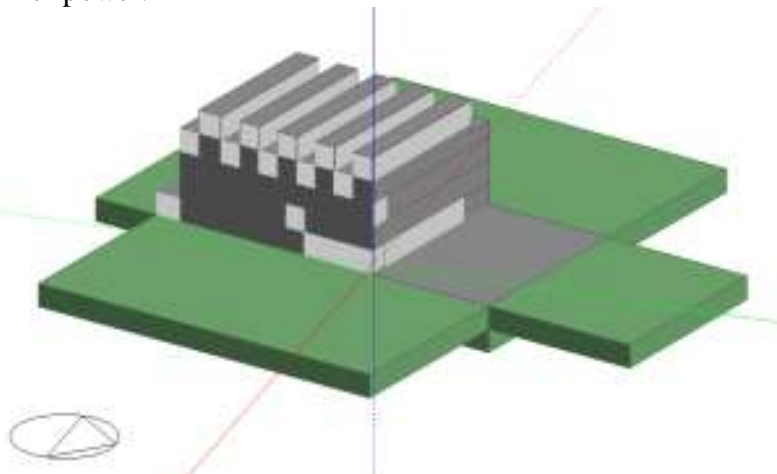

Fig. 7: Image of the modeling through the Design Builder tool.

The final calibration of the model could be made thanks to the real energy consumption data provided by the MUBAC management. The average energy consumption for the 2014-2016 period was $698,067 \mathrm{kWh} / \mathrm{a}$. Once the value of the lighting consumption, 4.8 $\mathrm{kWh} / \mathrm{m} 2 \mathrm{a}$, with an allocation of 300 lux, was deducted, the value of $669.85 \mathrm{MWh} / \mathrm{a}$ was obtained for the existing air-conditioning system, which means a value of $116.08 \mathrm{kWh} / \mathrm{m} 2 \mathrm{a}$. The same was done to adjust interior surface temperatures and interior air temperature [19]. It is necessary to indicate that the fact that the user does not have access to personalized changes in the air conditioning, and that there are fixed setpoint temperatures of $22^{\circ} \mathrm{C}$ in winter and $24^{\circ} \mathrm{C}$ in summer from 9:00 h. at 8:00 p.m. facilitated the calibration process.

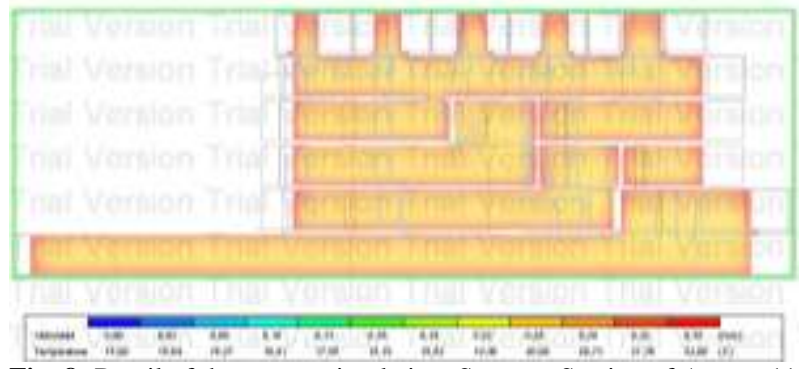

Fig. 8: Detail of the energy simulation. Summer Section of August 11th at 5:00 p.m.

Simulations of annual thermal behavior were made according to the estimation of the two MUBAC 1 and MUBAC 2 scenarios, but also the variable of consideration of the air renewal required in the CTE regulation was introduced for an occupation of 0.5 people per square meter of surface ( 2,886 people), given that it entailed a significant increase in the value of annual energy demand (Figs. 8 and 9). As indicated, the value of $1 \mathrm{ren} / \mathrm{h}$ was adopted, which is what is stipulated in the air conditioning project, in addition to an infiltration air rate of $0.7 \mathrm{ren} / \mathrm{h}$, based on the experience gained in measurements over 45 dwellings using the Blower door test in base $n 50$, wind pressure of 50 pascals [20].

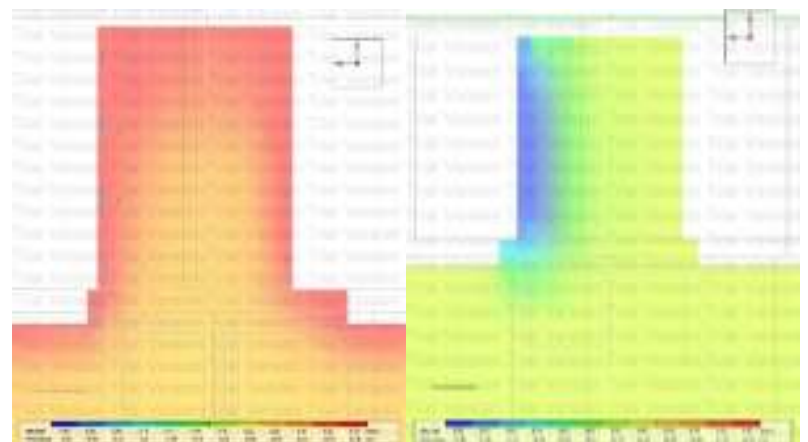

Fig. 9: Details of the thermal simulation of the skylights. (a) Summer of August 11th at 5:00 p.m. (b) Winter of January 28th at 5:00 p.m. 
The comparative results of the simulations carried out are shown in Table 1. As can be observed, the annual energy demand is reduced by $3.9 \%$ in the case of 2,886 people $(0.5$ persons per $\mathrm{m} 2)$, whereas it is 9.97 . \% for the renovation air estimate of $1 \mathrm{ren} / \mathrm{h}$ and average annual real occupation of 200 people. The biggest differences are appreciated for the summer regime, having considered, according to the usual experience in the Spanish Levante thing, seven months of refresher needs. Taking into account the cost of the electric mix of $0.123 € / \mathrm{kWh}$, with the MUBAC 2 façade solution, an annual energy saving of $€ 6,551$ would be produced.

Table 1: Calculation of annual energy demands and $\mathrm{CO} 2$ emissions of the two options.

\begin{tabular}{|c|c|c|c|c|}
\hline & $\begin{array}{c}\text { MUBAC } \\
\mathbf{1}\end{array}$ & $\begin{array}{c}\text { MUBAC } \\
\mathbf{2}\end{array}$ & $\begin{array}{c}\text { MUBAC } \\
\mathbf{1}\end{array}$ & $\begin{array}{c}\text { MUBAC } \\
\mathbf{2}\end{array}$ \\
\hline $\begin{array}{c}\mathbf{2 , 8 8 6} \\
\text { per. year } \\
\mathbf{5 . 6 2} \\
\text { ren/h }\end{array}$ & $\begin{array}{c}\mathbf{2 , 8 8 6} \\
\text { per. year } \\
\mathbf{5 . 6 2} \\
\text { ren/h }\end{array}$ & $\begin{array}{c}\mathbf{2 0 0} \text { per. } \\
\text { year } \\
\mathbf{1 . 0} \\
\text { ren/h }\end{array}$ & $\begin{array}{c}\mathbf{2 0 0} \text { per. } \\
\text { year } \\
\mathbf{1 . 0} \\
\text { ren/h }\end{array}$ \\
\hline $\begin{array}{c}\text { Energy demand in } \\
\text { summer (kWh/m2) }\end{array}$ & 127.8 & 125.8 & 62.48 & 58.55 \\
\hline $\begin{array}{c}\text { Energy demand in } \\
\text { winter (kWh/m2) }\end{array}$ & 138.97 & 130.65 & 32.68 & 27.37 \\
\hline $\begin{array}{c}\text { Annual Energy De- } \\
\text { mand (kWh/m2/year) }\end{array}$ & 266.85 & 256.45 & 95.16 & 85.93 \\
\hline $\begin{array}{c}\text { Annual CO2 emis- } \\
\text { sions at the Use Stage } \\
(\mathrm{kg})\end{array}$ & 536,368 & 515,464 & 191,271 & 172,719 \\
\hline Percentage (\%) & $\mathbf{1 0 0 . 0 0}$ & $\mathbf{9 6 . 1 0}$ & $\mathbf{1 0 0 . 0 0}$ & $\mathbf{9 0 . 0 3}$ \\
\hline
\end{tabular}

\section{Conclusion}

Large-format ceramic sheets have a better thermal performance than cast aluminum recycled panels, when applied as finishing layers on ventilated façades. The possibility of incorporating reflective enamels, which increase the reflectance of solar radiation by more than $250 \%$, prevents a greater thermal transmission in summer towards the inner layers of the enclosure, reducing the internal thermal admittance Y11 by $35 \%$. It also facilitates the incorporation of layers of thermal insulation of greater thickness when it is necessary to decrease the thermal transmittance $\mathrm{U}$ of the enclosure.

Once the model has been calibrated using the Design Builder tool, the value of the annual energy demand for the two ventilated façade solutions has been evaluated comparatively, with cast aluminum recycled panels and porcelain tile pieces. If we stick to the conditions imposed by the Spanish regulations, the CTE, applying an occupation of 0.5 people per square meter of useful area for fire protection reasons, the energy demand turns out to be almost 5 times greater than the actual energy demand, which it is around $116 \mathrm{kWh} / \mathrm{m} 2$ / year. It is shown that other occupation criteria should be adopted when designing and calculating the building's air conditioning system, and when carrying out the energy rating of the building according to the CTE HE- 1 standard. If an occupation of 200 people is adopted, and a renewal air rate of $1 \mathrm{ren} / \mathrm{h}$, for the calculation of the annual energy demand, this value is close to the actual energy consumption. The annual energy demand would be $96.16 \mathrm{kWh} / \mathrm{m} 2$ by year with the aluminum panels, compared to $85.93 \mathrm{kWh} / \mathrm{m} 2$ by year if the façade were ceramic and with $9 \mathrm{~cm}$. of insulation thickness. If this constructive solution had been used, a reduction in energy consumption of $9.97 \%$ would have been obtained, which would translate into annual cost savings costs $€ 6,551$, and reductions in $\mathrm{CO} 2$ emissions of $18,552 \mathrm{~kg}$. This alternative constructive solution would also reduce the energy incorporated in the materials, and by using materials manufactured in the Castellón region itself, it would considerably reduce the environmental impacts due to the energy needed to transport the materials.

\section{References}

[1] J. A. Márquez, M. M. Bohórquez, and S. G. Melgar, "A New Metre for Cheap, Quick, Reliable and Simple Thermal Transmittance (UValue) Measurements in Buildings," Sensors, vol. 17, no. 9, p. 2017, Sep. 2017.

[2] P. Hernandez and P. Kenny, "From net energy to zero energy buildings: Defining life cycle zero energy buildings (LC-ZEB)," Energy Build., vol. 42, no. 6, pp. 815-821, Jun. 2010.

[3] S. Firlagg and B. Zawada, "Impacts of airflows, internal heat and moisture gains on accuracy of modeling energy consumption and indoor parameters in passive building," Energy Build., vol. 64, pp. 372-383, Sep. 2013.

[4] A. Monge-Barrio and A. Sánchez-Ostiz, "Energy efficiency and thermal behaviour of attached sunspaces, in the residential architecture in Spain. Summer Conditions," Energy Build., vol. 108, pp. 244-256, Dec. 2015.

[5] O. P. Fanger, Thermal comfort. Analysis and applications in environmental engineering. Copenhagen, Denmark: McGraw-Hill, 1970.

[6] S. Domínguez, J. J. Sendra, A. L. León, and P. M. Esquivias, “Towards Energy Demand Reduction in Social Housing Buildings: Envelope System Optimization Strategies," Energies, vol. 5, no. 12, pp. 2263-2287, Jul. 2012.

[7] V. Echarri, M. Salvador, A. Espinosa, and G. M. Ramírez, "Lesiones en Paneles Fenólicos de Madera Baquelizada: Diagnóstico e Intervención," in Patorreb 2012: 4o Congreso de patología y rehabilitación de edificios : 12-14 de abril de 2012, Santiago de Compostela, 2012, ISBN 978-84-96712-49-2, pág. 45, 2012, p. 45.

[8] E. Bernat-Maso, L. Gil, P. Roca, V. Sarrablo, and C. Escrig, "Structural characterisation of textile ceramic technology used as a curtain wall,” Eng. Struct., vol. 57, pp. 277-288, Dec. 2013.

[9] Mansilla and Tuñon, Museo Bellas Artes Castellón, TC Cuadern. 2002.

[10] V. Echarri, A. Galiano, M. I. Pérez-Millán, and A. B. GonzálezAvilés, "Conditioning systems by radiant surfaces: comparative analysis of thermal ceramic panels versus the conventional systems in a museum," WIT Trans. Eng. Sci., vol. 83, pp. 287-301, 2014.

[11] ASCER and WEBER, Guía de la baldosa cerámica, 6a Edición. 2011.

[12] G. Silva, M. A. Bengochea, L. Guaita, C. Segarra, J. Corrales, and J. Corrales, "Eficiencia energética de fachadas ventiladas con baldosas cerámicas reflectantes al infrarrojo cercano," Inf. la Construcción vol. 68 , no. 544 , p. 160 , Dec. 2016.

[13] A.-H. Deconinck and S. Roels, "Comparison of characterisation methods determining the thermal resistance of building components from onsite measurements," Energy Build., vol. 130, pp. 309-320, Oct. 2016.

[14] CTE, Documento Básico HE 1. Ahorro de energía. Limitación de demanda energética. 2013.

[15] EPBD, "Directiva 2010/31/UE del Parlamento Europeo y del Consejo, de 9 de mayo de 2010, relativa a la eficiencia energética de los edificios." 2010.

[16] Código Técnico de la Edificación (CTE)., Reglamento de Instalaciones Térmicas en los Edificios, (RITE). ITC. 02.2.1.

[17] F. Salamone, L. Belussi, L. Danza, T. Galanos, M. Ghellere, and I. Meroni, "Design and Development of a Nearable Wireless System to Control Indoor Air Quality and Indoor Lighting Quality," Sensors, vol. 17, no. 5, p. 1021, May 2017.

[18] IDAE, "Consumos del Sector Residencial en España Resumen de Información Básica 2010-2011.”.

[19] V. Echarri Iribarren, A. L. Galiano Garrigós, and Á. B. González Avilés, "Ceramics and healthy heating and cooling systems: thermal ceramic panels in buildings. Conditions of comfort and energy demand versus convective systems," Inf. la Construcción, vol. 68(544): e, pp. 1-14, Dec. 2016.

[20] V. Echarri and Víctor, "Thermal Ceramic Panels and Passive Systems in Mediterranean Housing: Energy Savings and Environmental Impacts," Sustainability, vol. 9, no. 9, p. 1613, Sep. 2017. 